\title{
Review Article \\ MicroRNAs: New Regulators of Toll-Like Receptor Signalling Pathways
}

\author{
Xiaobing He, ${ }^{1}$ Zhizhong Jing, ${ }^{1}$ and Guofeng Cheng ${ }^{2}$ \\ ${ }^{1}$ State Key Laboratory of Veterinary Etiological Biology, Key Laboratory of Veterinary Public Health of Ministry of Agriculture, \\ Lanzhou Veterinary Research Institute, Chinese Academy of Agricultural Sciences, Lanzhou 730046, China \\ ${ }^{2}$ Key Laboratory of Animal Parasitology, Ministry of Agriculture, Shanghai Veterinary Research Institute, \\ Chinese Academy of Agricultural Sciences, Shanghai 200241, China
}

Correspondence should be addressed to Zhizhong Jing; zhizhongj@163.com and Guofeng Cheng; chenggfeng74@aliyun.com Received 15 November 2013; Revised 29 January 2014; Accepted 16 February 2014; Published 20 March 2014

Academic Editor: Yadong Zheng

Copyright ( 2014 Xiaobing He et al. This is an open access article distributed under the Creative Commons Attribution License, which permits unrestricted use, distribution, and reproduction in any medium, provided the original work is properly cited.

Toll-like receptors (TLRs), a critical family of pattern recognition receptors (PRRs), are responsible for the innate immune responses via signalling pathways to provide effective host defence against pathogen infections. However, TLR-signalling pathways are also likely to stringently regulate tissue maintenance and homeostasis by elaborate modulatory mechanisms. MicroRNAs (miRNAs) have emerged as key regulators and as an essential part of the networks involved in regulating TLR-signalling pathways. In this review, we highlight our understanding of the regulation of miRNA expression profiles by TLR-signalling pathways and the regulation of TLR-signalling pathways by miRNAs. We focus on the roles of miRNAs in regulating TLR-signalling pathways by targeting multiple molecules, including TLRs themselves, their associated signalling proteins and regulatory molecules, and transcription factors and functional cytokines induced by them, at multiple levels.

\section{Introduction}

Toll-like receptors (TLRs), an important family of pattern recognition receptors (PRRs), are responsible for the recognition of pathogen-associated molecular patterns from infectious pathogens. This recognition triggers the production of large amounts of inflammatory cytokines, type I interferons (IFNs), and antiviral proteins through the activation of interferon regulatory factor (IRF) 3 , IRF7, activator protein-1 (AP1 ), and nuclear factor-kappa B (NF- $\kappa \mathrm{B})$ [1-3]. In addition, the TLR-signalling pathways are strictly and finely regulated by positive or negative modulation at multiple levels to prevent excessive inflammation and achieve a balanced output $[2,4,5]$. Several mechanisms are responsible for the regulation of the TLR-signalling pathways. These include physical interactions, conformational changes, phosphorylation, ubiquitylation, and proteasome-mediated degradation involving various regulatory molecules $[2,4,5]$. Among the many regulatory molecules, microRNAs (miRNAs) have received considerable attention as a newly identified family of regulators involved in fine-tuning the TLR-signalling pathways [6-12].

miRNAs are a class of small noncoding RNAs (about 22 nucleotides in length) that regulate gene expression by binding to the $3^{\prime}$-untranslated regions (UTRs) of target messenger RNAs (mRNAs), typically resulting in protein translation repression or mRNA degradation [13-15]. miRNAs are involved into many biological processes, including development, differentiation, growth, homeostasis, stress responses, apoptosis, and immune activation, in organisms such as animals, plants, and even some DNA viruses [13-15]. To date, more than 30,000 miRNAs have been identified in at least 206 species. One prediction is that up to $30 \%$ of all human genes are regulated by miRNAs in many cell types, including immune and epithelial cells [13-15]. Therefore, miRNAs may serve as important regulators for controlling the differentiation of immune cells as well as the immune responses to pathogen infections [16-18]. Recent studies have indicated that miRNAs play important roles in regulating the TLR-signalling pathways and innate immune responses 
and function as immunomodulators for the complex regulatory networks [6-12]. Remarkably, many molecules that are involved in the TLR-signalling pathways (including signalling proteins, regulatory molecules, transcription factors, cytokines, and TLRs) are regulated by an array of miRNAs (Figure 1) [6-12].

Here, we review the recent findings regarding the relationship between miRNAs and the TLR-signalling pathways. Overall, we summarize the current understanding of the mechanisms of TLR-signalling pathways regulated by miRNAs. Then, we focus on the roles of miRNAs in regulating the TLR-signalling pathways by targeting TLRs themselves, their associated signalling proteins and regulatory molecules, and transcription factors and functional cytokines induced by them.

\section{Regulation of miRNA Expression by the TLR-Signalling Pathways}

Many studies have demonstrated that miRNAs expression profiles are subject to change in different cell lines when stimulated by the ligands in the TLR-signalling pathways. Briefly, in 2006, Baltimore Lab first documented that the upregulated expression of miR-146a, miR-155, and miR-132 in human monocytes is related to stimulation with the lipopolysaccharide (LPS) [19]. Subsequent studies found that miR-223, miR147, miR-9, miR-27b, and let-7e are induced by stimuli from other TLRs, by pathogen infection, and by IL- $\beta[52,57-$ 59]. Furthermore, several miRNAs such as miR-155, miR-146, and miR-21 are able to target some molecules involved in the TLR-signalling pathways, although the expression of some of these miRNAs depends on the stimulation by TLR ligands $[6,8,20,21]$. It is also noted that miRNAs may also induced in a temporal-specific manner. For example, miR-146 and miR155 are highly expressed within $2 \mathrm{~h}$ after LPS treatment and are thus early-response miRNAs, whereas miR-21 is expressed in macrophages at a later time after LPS treatment and is thus a late-response miRNA $[6,8,9,19-21,63]$. The different expression of these miRNAs in TLR-induced cells may also be attributed to the duration of treatment, the technology used, and the different cell types. Nonetheless, these studies clearly indicate that molecules involved in the TLR-signalling pathways can regulate miRNA expression (Table 1).

To date, almost all of miRNA expressions appearto depend on the TLR-induced NF- $\kappa \mathrm{B}$ and MAPK pathways (Table 1). In 2006, miR-146a was the first reported miRNA whose expression depends on the NF- $\kappa$ B pathway in human THP-1 monocytes after LPS stimulation [19]. Since then, many studies have further identified subsets of miRNAs related to the TLR-induced NF- $\kappa \mathrm{B}$-dependent pathway. The expression of many miRNAs including miR-146a, miR-155, miR-132, miR-223, miR-147, miR-9, miR-27b, let-7e, miR21, miR-16, miR-23b, miR-30b, miR-301a, and miR-125b is induced in an NF- $\kappa \mathrm{B}$-dependent manner after TLR stimulus or pathogen infection $[10,19-23,36-39,49,50,53,57-$ $64,70]$. For example, miR-9 expression is directly induced by LPS via the TLR4-MyD88-NF- $\kappa$ B-dependent pathway in human monocytes and neutrophils [58]. In addition, miR155 expression is induced in the NF- $\kappa \mathrm{B}$-dependent manner in various cell types after many stimuli, including LPS and LMP1, the viral latent protein of the Epstein-Barr virus (EBV) $[36,37]$. miR-146a expression can also be induced through the $\mathrm{NF}-\kappa \mathrm{B}$-dependent pathway in response to various immune mediators, such as LPS, IL- $1 \beta$, LMP1, and tumour necrosis factor- (TNF-) $\alpha[19,22,23,39]$. Conversely, some miRNAs (miR-29b, let-7i, miR-98, miR-107, miR-27a, and miR-532-5p) are downregulated by the TLR-induced NF- $\kappa \mathrm{B}$-dependent pathway $[39,72-77,120]$. It is necessary to point out that miR-125b expression related to the TLR-activated NF- $\kappa \mathrm{B}-$ dependent pathway remains controversial and needs to be further investigated in the future [40].

The MAPK pathway is also involved in regulating miRNA expression (Table 1). For example, miR-21, miR-146b, miR155 , and miR-146b-5p are reportedly upregulated through the heterodimers Fos and Jun in different cell types in response to various stimuli $[36,41,65,66,71,121]$. In contrast, the MAPK pathway is also involved in the downregulation of miRNA expression, for example, miR-99a [24]. However, other cellular pathways are also responsible for regulating miRNA expression. For example, the expression of miR-132 is regulated by the cyclic AMP response element-binding protein and the transcriptional coactivator p300 [50]. Expression of miR-143/145 cluster is downregulated by the Janus kinase 1 (JAK1) - signal transducer and activator of transcription 1 (STAT1)—dependent pathway [85].

Since the expressions of most TLR-responsive miRNAs are related to the corresponding ligand stimulation or the infection of some pathogens, it is reasonable to conclude that these miRNAs may be not only involved in regulating the innate immune responses, ensuring host protection, but also play important roles in the pathogenesis of some infectious diseases. Because TLR and miRNA expression profiles are limited to certain cell types, the different TLR distributions in different immune cells might also have different miRNA expressions. Currently, our understanding of the TLR-induced miRNAs has significantly expanded, with breakthroughs providing insights into the finely tuned miRNA-mediated regulation of the TLR-signalling pathways.

\section{3. miRNA-Mediated Regulatory TLR-Signalling Pathways}

miRNAs regulate TLR-signalling pathways at several layers, including regulation of TLR expression, TLR-associated signalling proteins and regulatory molecules, and TLR-induced transcription factors and functional cytokines (Figure 1).

3.1. miRNAs-Mediated Regulatory TLR Expression. It is well recognized that the activation of TLR-signalling pathways is required for hosts to eliminate invading pathogens. However, excessive activation of these pathways may also disrupt immune homeostasis, leading to some diseases such as autoimmune diseases, chronic inflammatory diseases, or cancer $[2,4,5]$. Therefore, precise regulation of TLR-signalling pathways is especially important [6-12]. Since miRNAs act as a class of key regulators of gene expression, the regulation of TLR expression may be one of the effective points at which miRNAs target TLRs (Table 2). 





TABLE 2: Verified targets of miRNAs in TLR-signalling pathway.

\begin{tabular}{|c|c|c|}
\hline Target mRNA & miRNA(s) & Reference \\
\hline \multicolumn{3}{|l|}{ Receptors } \\
\hline TLR4 & let-7i, let-7e, miR-223, miR-146a, miR-146b, miR-511 & {$[25,53,62,72,78,79]$} \\
\hline TLR3 & miR-223, miR-26a & {$[53,80]$} \\
\hline TLR2 & miR-105, miR-19a/b, miR-143, miR-146a & {$[81-84]$} \\
\hline \multicolumn{3}{|l|}{ Signalling proteins } \\
\hline IRAK1 & miR-146a, miR-146b, miR-21 & {$[19,26,28,31,85]$} \\
\hline TRAF6 & miR-146a, miR-146b & {$[19,26,79]$} \\
\hline IRAK2 & miR-146a & {$[19,26]$} \\
\hline MyD88 & miR-146b, miR-155, miR-200b, miR-200c, miR-21, miR-149, miR-203 & {$[29,30,54,79,86-88]$} \\
\hline IRAK4 & miR-146a, miR-132, miR-212 & {$[51]$} \\
\hline TRAF4 & $\operatorname{miR}-29$ & {$[89]$} \\
\hline FADD & miR-155 & {$[38,40]$} \\
\hline $\mathrm{IKK} \beta$ & miR-155, miR-199a & {$[38,40,54,88]$} \\
\hline $\mathrm{IKK} \varepsilon$ & miR-155 & {$[38,40]$} \\
\hline TAB2 & miR-155 & {$[38,40]$} \\
\hline RIPK1 & miR-155 & {$[38,40]$} \\
\hline TIRAP & miR-145 & [31] \\
\hline BTK & miR-348 & {$[69,90]$} \\
\hline $\mathrm{IKK} \alpha$ & $\operatorname{miR}-223$ & [91] \\
\hline MKK4 & $\operatorname{miR}-92 a$ & {$[92]$} \\
\hline STING & miR-24 & {$[56]$} \\
\hline ISGs & miR-132 & {$[50]$} \\
\hline \multicolumn{3}{|c|}{ Transcription factors } \\
\hline P38 MAPK & miR-155 & {$[38]$} \\
\hline $\mathrm{NF}-\kappa \mathrm{B} 1$ & miR-9, miR-210 & {$[58,93]$} \\
\hline NF- $\kappa$ Bp 65 & $\operatorname{miR}-329$ & [94] \\
\hline STAT3 & miR-17-5p, miR-20a, miR-223 & {$[55,95]$} \\
\hline $\mathrm{C} / \mathrm{EBP} \beta$ & miR-155 & {$[32,33]$} \\
\hline $\operatorname{PPAR} \gamma$ & $\operatorname{miR}-27 b$ & [59] \\
\hline p300 & miR-132 & {$[50]$} \\
\hline FOXP3 & miR-155 & {$[34]$} \\
\hline Ets2 & miR-155 & {$[96]$} \\
\hline \multicolumn{3}{|c|}{ Functional cytokines } \\
\hline IL-8 & miR-146a, miR-16 & {$[22,97]$} \\
\hline RANTES & miR-146a & [22] \\
\hline IFN- $\alpha$ & $\operatorname{miR}-4661$ & {$[98]$} \\
\hline IFN- $\beta$ & let-7b, miR-26a, miR-34a, miR-145 & {$[11,99]$} \\
\hline TNF & miR-125b, miR-187, miR-16, miR-221, miR-579, miR-369-3, miR-155 & {$[40,42,67,97,100-102]$} \\
\hline IL-6 & miR-16, miR-365, miR-142-3p, miR-187 & {$[11,73,103,104]$} \\
\hline IL-10 & miR-106a, miR-106b, miR-466l & {$[105,106]$} \\
\hline IL-12p35 & miR-21 & {$[107-109]$} \\
\hline IFN- $\gamma$ & miR-9, miR-21 & {$[108,110]$} \\
\hline IL-12p40 & miR-187, miR-21 & {$[108,109]$} \\
\hline \multicolumn{3}{|c|}{ Regulators molecules } \\
\hline ACHE & $\operatorname{miR}-132$ & {$[49]$} \\
\hline PDCD4 & miR-21 & {$[63,111,112]$} \\
\hline SHIP1 & miR-155 & {$[32,33,43-46,62,111,112]$} \\
\hline SOCS1 & miR-155 & {$[47,48,62,113]$} \\
\hline Notchl & miR-146a & {$[35]$} \\
\hline CaMKIIalpha & miR-148a/b, miR-152 & {$[114]$} \\
\hline
\end{tabular}


TABLE 2: Continued.

\begin{tabular}{llc}
\hline Target mRNA & miRNA(s) & Reference \\
\hline PCAF & miR-181, miR-17/92 & {$[115,116]$} \\
CIS & miR-98, let-7 & {$[75,117,118]$} \\
SOCS4 & miR-98, let-7 & {$[75,117,118]$} \\
SOCS3 & miR-203 & {$[118]$} \\
MKP-1 & miR-101 & {$[119]$} \\
\hline
\end{tabular}

IRAK: IL-1R-associated kinase; TRAF6: TNFR-associated factor 6; MyD88: myeloid differentiation primary-response protein 88; FADD: Fas-associated death domain protein; IKK: inhibitor of NF- $\kappa$ B kinase; TAB2: TAK1-binding protein 2; RIPK1: receptor TNFR-interacting serine-threonine kinase 1; TIRAP: TIR domain-containing adaptor protein (also known as MAL, MyD88 adaptor-like protein); BTK: Bruton's tyrosine kinase; MKK4: mitogen-activated protein kinase kinase 4; STAT3: transcription factor signal transducer and activator of transcription 3; C/EBP $\beta$ : CCAAT/enhancer-binding protein- $\beta$; PPAR $\gamma$ : peroxisome proliferator-activated receptor- $\gamma$; RANTES: regulated upon activation normal T cell expressed and presumably secreted; FOXP3: forkhead box P3; Ets2: E26 transformation-specific sequence 2; STING: stimulator of interferon genes; ACHE: acetylcholinesterase; PDCD4: programmed cell death 4; SHIP1: Src homology 2 (SH2) domain-containing inositol-5' -phosphatase 1; SOCS: suppressor of cytokine signalling; CIS: cytokine-inducible Src homology 2; CaMKIIalpha: calcium/calmodulin-dependent protein kinase II; PCAF: protein-associated factor; MKP-1: MAPK phosphatase-1.

To date, several miRNAs have been shown to regulate TLR expression. Among them, the let-7 miRNA family, including let-7e and let-7i, can regulate TLR4 expression. Overexpression of let-7e by miRNA mimics resulted in the downregulation of TLR4 expression in mouse peritoneal macrophages, and inhibition of let-7e by antisense miRNA led to the upregulation of TLR4 expression [62]. Let-7i regulates TLR4 expression in human biliary epithelial cells [72]. This different member of the let-7 miRNA family is found in macrophages and epithelial cells, where it regulates TLR4 expression, probably due to the differences in the TLR-induced miRNA expression profiles of different cell types. Another TLR-induced miRNA, the myeloid-specific miR-223, can regulate both TLR4 and TLR3 expression in granulocytes [53]. A recent study found that miR-146a can also negatively regulate TLR4, resulting in accumulation of oxidized low-density lipoprotein (oxLDL) accumulation and an inflammatory response in macrophages [25]. In addition, miR-511 functions as a putative positive regulator of TLR4 under cell cycle arrest conditions, whereas it seems to inhibit TLR4 expression under similar conditions in monocytes and dendritic cells (DCs) [78]. Moreover, miR-26a can negatively regulate the TLR3 signalling pathway by targeting TLR3 expression in rat macrophages and ameliorates pristane induced arthritis in rats [80].

TLR2 is another receptor regulated by miRNAs (Table 2). The expression of TLR2 is negatively regulated by miR-146a and miR-105, respectively $[81,82]$. In addition, miR-19a/b upregulates TLR2 expression in fibroblast-like synoviocytes of rheumatoid arthritis patients [83]. Overexpression of miR$19 \mathrm{a} / \mathrm{b}$ by miRNA mimics not only reduces TLR2 protein expression but also significantly inhibits the activities of the TLR2-triggered cytokines and kinases [83]. Furthermore, miR-143 can inhibit the expression of TLR2, leading to the suppression of the invasion and migration of a subset of human colorectal carcinoma cells [84].

Overall, these studies suggest that miRNAs play an important role in the constitutive expression of TLRs. Further mining of other TLRs regulated by miRNAs is still needed. Nevertheless, miRNA regulatory TLR downstream signalling molecules and/or transcription factors seem more effective than miRNAs directly targeting TLRs to abolish receptor expression and thus completely shut down the TLR-signalling pathway.

\section{2. miRNA-Mediated Regulatory TLR-Associated Signalling} Proteins. TLRs recruit many types of proteins for these signalling pathways upon ligand binding. These proteins include adaptor molecules [myeloid differentiation factor 88 (MyD88), Toll/Interleukin-1 receptor (TIR) domain-containing adapter molecule (TRIF), TIR domain-containing adaptor protein (TIRAP), and TRIF-related adaptor molecule (TRAM)], various kinases [IL-1R-associated kinases (IRAKs), Bruton's tyrosine kinase (BTK), MAPK kinases (MKKs), TAK1-binding proteins (TABs), and $\mathrm{I} \kappa \mathrm{B}$ kinases (IKKs)], and ubiquitin ligases [TNFR-associated factors (TRAFs)]. Recently, these molecules have also been shown to be targeted by a set of miRNAs, especially the TLR-induced miRNAs [1-12] (Table 2).

Among these miRNAs identified, miR-146a, one of key TLR-induced miRNAs, inhibits the TLR-signalling pathway by targeting IRAK1 kinase and TRAF6 ligase [19, 26-28, 85]. IRAK1 and TRAF6 are the important components of the MyD88-dependent pathway for activating most TLRsmediated signalling pathways (except TLR3) in many cell types, including the THP-1 cell line [9, 19, 26-28]. Recently, IRAK2, another IL-1R-associated kinase, has also been shown to be regulated by miR-146a, although its relevance in the TLR-signalling pathways remains to be further determined $[19,26]$. In addition, miR-146a can inhibit IL-8 expression, suggesting that this negative regulation might be an important mechanism of severe inflammation during the innate immune response [22]. Moreover, miR-146b, another miRNA of the miR-146 family, is an IL-10-responsive miRNA with anti-inflammatory activity [79]. miR-146b can modulate the TLR4-signalling pathway by directly targeting multiple proteins, including TLR4, MyD88, IRAK1, and TRAF6 [79]. This modulation leads to a significant reduction of several inflammatory cytokines and chemokines. The third IL-1Rassociated kinase, IRAK4, has been shown to be targeted by miR-132, miR-212, and miR-146a, decreasing the production of inflammatory cytokines [51]. A recent study demonstrated 


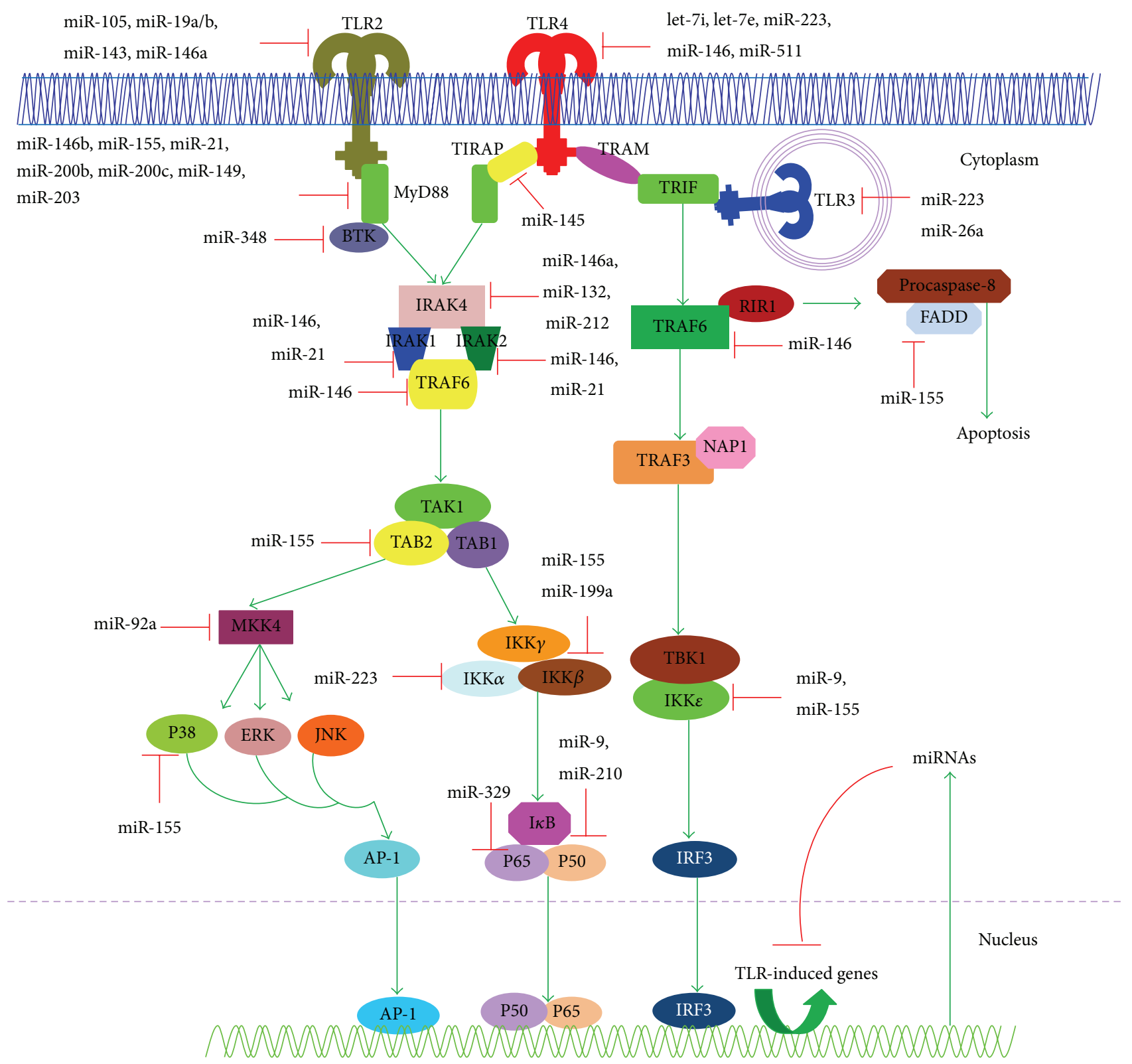

FIgURE 1: The fine-tuning of the TLR-signalling pathways by miRNAs. An array of miRNAs are involved in regulating of the TLR-signalling pathways and innate immune responses by targeting multiple molecules at multiple levels, including TLRs themselves, TLR-associated signalling proteins, TLR-associated regulatory molecules, TLR-induced transcription factors, and TLR-induced functional cytokines.

that miR-29 as tumor suppressor miRNA is one of the negative regulators of TRAF4 expression in metastatic prostate cancer [89].

miR-155, another important TLR-induced miRNA, can target some of several signalling proteins in TLR-signalling pathways. These proteins mainly include some of the components of the NF- $\kappa$ B pathway, such as Fas-associated death domain protein, IKK $\beta$, IKK $\varepsilon$, and the receptor- (TNFR superfamily) interacting serine-threonine kinase 1 [38, 40]. Next, miR-155 has been shown to inhibit the p38 MAPK signalling pathway and inflammatory cytokine production in human DCs in response to microbial stimuli [38]. Furthermore, miR155 can regulate TAB2 (a signalling molecule downstream of TRAF6) in human monocyte-derived DCs [38]. Recently, MyD88 has been shown to be regulated by miR-155, miR-149, and miR-203 [29, 30, 86, 87]. In addition, TIRAP (also known as MAL), another MyD88 adaptor-like protein that acts as a bridging adaptor for TLR2- and TLR4-mediated MyD88dependent signalling pathways, has been identified as a target of miR-145 in hematopoietic stem/progenitor cells [31].

In addition to previously described miRNAs, the miR-200 family (such as miR-200b and miR-200c) can also regulate the expression of MyD88. This regulation can modify the efficiency of the TLR4-signalling pathway and thus affect host innate defences against microbial pathogens [88]. miR-21 also inhibits the expression of MyD88 and IRAK1, leading to the 
upregulation of the JNK/c-Jun signalling pathway, the ERK/cFos pathway, and signalling by type I IFNs during RNA virus infection [54]. In addition, miR-346 can target Bruton's tyrosine kinase (BTK), a critical tyrosine kinase involved in the TLR4, TLR7, TLR8, and TLR9 signalling pathways for NF- $\kappa \mathrm{B}$ activation $[69,90]$. Next, miR-223 has been shown to target IKK $\alpha$ (one of the serine-threonine kinases in the canonical $\mathrm{NF}-\kappa \mathrm{B}$ pathway) in human monocytes/macrophages [91]. miR-199a can target IKK $\beta$ (another serine-threonine kinase) in human ovarian cancer cells and/or endometrial stromal cells, leading to suppression of the NF- $\kappa$ B pathway activation and reduced IL- 8 production $[122,123]$. Moreover, miR-92a can target mitogen-activated protein kinase kinase 4 and thus inhibit the TLR4-triggered inflammatory response in macrophages [92].

Collectively, some of the key components of TLRsassociated signalling proteins are regulated by certain miRNAs, although relatively few signalling proteins have been identified so far. These studies suggest that miRNA could result in timely and appropriate toning down and/or termination of the TLR-signalling pathway by targeting critical signalling proteins, once a TLR is triggered.

\section{3. miRNA-Mediated Regulatory TLR-Induced Transcription}

Factors. Activation of certain transcription factors, such as IRF, NF- $\kappa \mathrm{B}, \mathrm{AP}-1$, and STAT, is a key functional step for TLR-signalling pathways. Theoretically, targeting transcription factors by miRNAs may globally affect TLR-induced gene expressions. Many studies have experimentally demonstrated that miRNA also plays a vital role in regulation of TLR-induced transcription factors [124, 125]. As discussed above, miRNAs induced by certain TLRs-activated transcription factor-dependent signalling pathways usually provide feedback to regulate their activation. Many studies reveal that miRNAs directly and/or indirectly regulate the expressions of TLR-activated transcription factors [6-12] (Table 2). Generally, NF- $\kappa \mathrm{B}$ is considered the most important transcription factor in TLR-induced signalling pathways. It has been demonstrated that miR-9 (one of the TLRresponsive miRNAs) directly targets NF- $\kappa \mathrm{B} 1$ mRNA [58]. Because the TLR4 agonist LPS induces miR-9 expression in a MyD88- and NF- $\kappa$ B-dependent pathway manner, miR-9mediated feedback may control the TLR-signalling pathways by fine-tuning NF- $\kappa \mathrm{B} 1$ expression [58]. In addition, a recent study has also demonstrated that miR-210 can target NF$\kappa \mathrm{B} 1$ under induction by LPS in murine macrophages [93]. Furthermore, miR-329 plays a pivotal role in the inhibition of IL- 6 mRNA expression by targeting the NF- $\kappa$ Bp65 [94].

miRNA can also target other TLR-activated transcription factors. For example, miR-17-5p and miR-20a in myeloidderived suppressor cells can target STAT3 and thus alleviate the suppressive function of myeloid-derived suppressor cells [95]. In addition, miR-223 has also been shown to target STAT3, resulting in the inhibition of the proinflammatory cytokines IL-6 and IL-1 $\beta$ production in macrophages [55]. Recently, a transcriptional corepressor CCAAT/enhancer binding protein- $\beta$ has been identified as a target of miR-155. The effect of miR-155 leads to decreasing the expression levels of granulocyte colony-stimulating factor and possibly IL-6 in splenocytes $[32,33]$. Another transcriptional coactivator, p300, which often associates with the cAMP-responsive element-binding protein, is targeted by miR-132 in lymphatic endothelial cells infected with Kaposi's sarcoma-associated herpesvirus [50]. Furthermore, Forkhead box p3 (a transcription factor required for the regulatory $\mathrm{T}$ cells) and E26 transformation-specific sequence 2 have also been identified as targets of miR-155 [34, 96]. Interestingly, when induced by the NF- $\kappa \mathrm{B}$-dependent pathway, miR-27b directly targets peroxisome proliferator-activated receptor $\gamma$ and inhibits LPS-induced TNF secretion after LPS treatment [59].

3.4. miRNA-Mediated Regulatory TLR-Induced Cytokines. Activation of TLR signalling through recognition of pathogen-associated molecular patterns leads to the transcriptional activation of genes encoding for proinflammatory cytokines, chemokines, and costimulatory molecules. These cytokines play an important role in eradicating infectious pathogens and recruiting inflammatory cells to the infection site for effective host defence. Several key TLR-induced functional cytokines such as type I IFNs, TNF, IL-6, IL-12, and IL-10 have been demonstrated to be regulated by miRNAs. Bioinformatics analysis also indicated that the mRNAs encoding these cytokines and chemokines have the binding sites for miRNAs [126-128] (Table 2).

A recent study demonstrated that miR-146a sequentially suppresses the production of type I IFNs, TNF, IL- $1 \beta$, and IL6 by targeting IRAK1, IRAK2, and TRAF6 in macrophages during vesicular stomatitis virus (VSV) infection or during LPS tolerance [26-28]. In addition, miR-466l can directly bind to the $3^{\prime}$-UTR of IFN- $\alpha$ and thus reduce IFN- $\alpha$ expression during VSV and EBV infections [98]. Moreover, miR-26a, miR-34a, miR-145, and let-7b directly regulate the expression of IFN- $\beta$ by targeting the IFN- $\beta 3^{\prime}$-UTR $[11,99]$. On the other hand, certain cytokines such as type I IFNs can also affect miRNA expression. For example, the activation of IFN- $\alpha$ can suppress two abundantly expressed miRNAs, miR-378 and miR-30e. This suppression allows release of cytolytic mRNAs, resulting in augmented natural killer cell cytotoxicity [129]. Furthermore, miRNAs can affect antiviral immunity through modulating IFN downstream signalling. For example, owing to the absence of a miR-29a cluster in the thymic epithelium, high expression of IFN- $\alpha$ receptor in the thymic epithelium triggers suboptimal signalling and then results in a rapid loss of thymic cellularity [130]. In addition, miR-132 has been shown to perform a negative effect on the expression of interferon-stimulated genes, facilitating viral replication [50].

Aside from type I IFNs, TNF mRNA contains a binding site that can be targeted by miR-125b in mouse RAW 264.7 macrophages [40]. Recently, it has been demonstrated that miR-187 directly targets TNF- $\alpha$ mRNA and indirectly decreases IL-6 and IL-12p40 expression via downmodulation of $\mathrm{I} \kappa \mathrm{B} \zeta$, a master regulator of the transcription of these latter two cytokines [100]. Next, it has been shown that IL-6 can be targeted by several miRNAs such as miR-16, miR-365, and miR-142-3p, subsequently reducing the endotoxin-induced mortality by restricting TLR signalling through a feedback mechanism $[11,103,104]$. In addition, bioinformatics analysis 
indicates that the $3^{\prime}$-UTR of the IL-6mRNA contains a let-7binding site. However, many let-7 family miRNAs can usually be suppressed after TLR stimulation, suggesting that let7 may contribute to the expression of IL-6 [73]. But, the relationship between the let-7 family and IL- 6 remains to be experimentally determined. Another study has shown that IL-10 is also regulated by miR-106a and miR-106b in human Burkitt's lymphoma Raji cell line and that IL-12p35 mRNA contains a target site for miR-21 in macrophages and DCs, as confirmed by reporter assays, leading to restricted adaptive Th1 responses [105, 107-109]. In contrast, miR-29 suppresses immune responses against intracellular pathogens by targeting IFN- $\gamma$ [110].

Stability of proteins is very important for their biological function. Increasing evidence indicates that miRNAs, together with RNA-binding proteins (RBPs), regulate the stability of numerous cytokine-encoding mRNAs and/or their translation through the AU-rich elements (AREs) of their $3^{\prime}$-UTR regions. For example, both TNF and IL10 mRNAs contain long AREs targeted by tristetraprolin (TTP), a key factor in mRNA destabilization downstream of the TLR-signalling pathway $[67,68]$. In addition, miR-16 cooperates with TTP to mediate TNF mRNA destabilization [97]. Furthermore, a recent study showed that TNF mRNA is directly degraded by miR-221, miR-579, and miR-125b with TTP, leading to LPS tolerance $[40,101]$. Among these miRNAs, miR-221 interacts with TTP to accelerate TNF mRNA decay, whereas miR-579 and miR-125b combine with TTP to block TNF mRNA translation [40, 101]. However, some of these effects could result from the upregulation of miR-125b expression [40].

Conversely, miRNAs can also compete with RBPs to protect cytokine-encoding mRNAs from destabilization. For example, miR-466l competes with TTP to bind to the canonical ARE "AUUUA" sequence in IL-10 through its seed region. This binding effect protects the IL-10 mRNA from TTPmediated degradation [106]. Interestingly, environmental factors are also involved in cytokine-mediated stability of encoding mRNA. For example, under serum starvation, miR369-3 directly interacts with the ARE in TNF mRNA to initiate TNF mRNA translation, and this interaction depends on the recruitment of the fragile-X mental retardation-related protein 1 and argonaute 2 [102]. In contrast, miR-369-3 represses the expression of TNF when the cells are actively proliferating [42]. It has also been shown that miR-155 is required for TNF mRNA stabilization, as miR-155-deficient B cells and/or miR-155-deficient mice fail to produce increased levels of TNF after LPS injection, although a direct binding site for miR-155 in the TNF mRNA has not yet been identified $[40,42]$. In addition to the insights discussed above, further studies are needed to elucidate whether other TLR-responsive cytokines are subject to feedback regulation by miRNAs.

3.5. miRNA-Mediated Regulatory TLR-Associated Regulatory Molecules. miRNAs can target TLR-associated regulatory molecules for regulating TLR-signalling pathways (Table 2). A recent study indicated that miR-132 can target acetylcholinesterase (ACHE), a key regulator of TLR-signalling pathways, to increase the acetylcholine-mediated negative regulation of TLR-signalling pathways [49]. Next, miR-21 targets tumour suppressor protein programmed cell death 4 (PDCD4), an inhibitor of eukaryotic translation initiation factor $4 \mathrm{~F}$, in macrophages, thus enhancing innate immune responses in the early phase of pathogen infections $[63,111$, 112]. In addition, the inhibition of PDCD4 expression by miR-21 increases IL-10 secretion, suggesting complex roles of TLR-induced cytokine production in pathogen infections $[63,111,112]$. Moreover, Src homology 2 domain-containing inositol-5' ${ }^{\prime}$-phosphatase 1 (SHIP1), a negative regulator of TLR-signalling pathways and inflammatory responses, has been identified as a target of miR-155 [33, 43-45]. The increased expression of miR-155 in response to LPS stimulation or pathogen infection in macrophages accompanies the decreased expression of SHIP1 [32, 43-46, 111, 112]. Furthermore, miR-155 has also been shown to target suppressor of cytokine signalling 1 (SOCS1), which is another negative regulator of TLR-signalling pathways [47, 48, 113]. The expression of miR-155 is also upregulated in macrophages during RNA virus infection, and upregulation of miR-155 provides positive feedback regulation to TLR3- and TLR4triggered antiviral innate immune responses by promoting type I IFNs signalling via targeting of SOCS1 $[47,113]$. However, IL-10 inhibition of miR-155 expression increases SHIP1 and SOCS1 expression and mitigates TLR signalling [47, 48, 62]. Overall, these findings indicate that miR-155 expression is upregulated and inhibits the expression of the negative regulators SHIP1 and SOCS1 in the early phase of TLR4 and endosomal RNA-sensing TLR activation, allowing TLR signal transduction and cytokine production. Later in the response, the increased miR-21 induces IL-10 production by repressing PDCD4 expression, and IL-10 then feeds back to the pathway to reduce miR-155 expression, thereby increasing SHIP1 and SOCS1 expression and limiting the TLR4 and endosomal RNA-sensing TLR-signalling pathways.

Many other miRNAs also target other regulatory molecules involved in regulating the TLR-signalling pathways (Table 2). Notch1, a known positive regulator of IL-12p70 production in DCs, has been confirmed as a target of miR-146a. miR-146a targeting Notch1 suppresses IL12 p70 production in TLR9-triggered DCs [35]. In addition, $\mathrm{miR}-148 \mathrm{a} / \mathrm{b}$ and miR-152 can inhibit the expression of calcium/calmodulin-dependent protein kinase II, and thus they regulate TLR-signalling pathways [114]. Furthermore, miR-181 and miR-17/92 suppress TNF-induced cytokine production in epithelial cells by targeting p300/cyclic AMP response element-binding protein-associated factor that is a coactivator and acetyltransferase that promotes histone acetylation and gene transcription $[115,116]$. Cytokineinducible Src homology 2 (CIS) protein and SOCS4, as the regulatory molecules, have been identified as direct targets of miR-98 and let-7. Furthermore, LPS stimulation and the pathogen (Cryptosporidium parvum, C. parvum) infection can induce CIS and SOCS4 expression by downregulating miR-98 and let-7 expression in biliary epithelial cells $[75,117$, 118]. These studies suggest that miRNAs may be responsible for coordinately regulating the CIS and SOCS expression in human biliary epithelial cells, but the roles of miRNAs in regulating the CIS and SOCS expression can be changed 
after C. parvum infection. Interestingly, TLR-dependent induction of miR-101 appears to provide positive feedback loop control of innate immune responses through miR-101mediated suppression of MAPK phosphatase 1, an inhibitory regulator of TLR-signalling pathways [119]. Thus, miRNAs are responsible for regulating regulatory molecules to fine-tune TLR-signalling pathways and downstream events.

\section{Summary}

Over the past decade, significant progress has been made in our understanding of the roles of miRNAs in the immune system. The functions of miRNAs have been investigated in detail, particularly in regulating TLR-signalling pathways and innate immune responses by targeting multiple molecules at multiple levels. Subtle differences in TLR-induced miRNA expression profiles revealed by a number of studies have been found to be closely related to ligands, as well as correlated with treatment time, technology used, and cell types. However, the mechanisms regarding TLR-signalling pathwaysmediated miRNA expression regulation, through transcriptional repression or posttranscriptional destabilization, need to be further deeply investigated. Given the multifunctional roles of miRNAs in TLR-signalling pathways, miRNA targeting these pathways appears relatively more effective, economical, and common rather than completely shutting them down by abolishing receptor and cytokines expression.

Importantly, studying the central roles of miRNAs in regulating TLR-signalling pathways indicates that TLRsignalling pathways induce multiple miRNAs, which in turn regulate the strength, location, and timing of the TLRsignalling pathways, and might be involved in controlling the switch from a strong early inflammatory response to the resolution phase of the inflammatory process in a timely and orchestrated manner. The innate immune system utilizes multiple miRNAs to properly regulate its functional capacity, creating a finely tuned balance between activation and repression in TLR-signalling pathways. Interestingly, several miRNAs work together with RBP to regulate TLR-responsive mRNA stability and translation in different ways. These findings open up an exciting new area in the regulation of TLR-signalling pathways.

Besides the TLR-signalling pathways, some miRNAs, such as miR-146a, miR-466l, miR-24, miR-122, miR-378, miR30 e, miR-29a, and miR-223, are induced by signalling pathways of retinoic acid-inducible gene-I- (RIG-I-) like receptors and/or nucleotide-binding oligomerization domain- (NOD-) like receptors. Furthermore, they use feedback mechanisms to regulate these signalling pathways and downstream events $[26,56,98,99,130-135]$. However, the roles of miRNAmediated regulation are only beginning to emerge. A wide variety of pathogens, especially DNA viruses, express the highest number of miRNAs, and then these miRNAs directly modulate PRR-signalling pathways and innate immune responses to establish a cellular environment conducive for viral infection and replication [134, 136-141]. More strikingly, a number of studies have revealed that several miRNAs, such as miR-21, miR-29a, and let-7b, can even serve as physiological ligands of the single-stranded RNA-sensing
TLRs [142-146]. However, the precise regulatory roles of miRNAs in PRR-mediated signalling pathways and innate immune responses are still not fully understood, especially how these miRNA networks interact to optimize PRRsignalling pathways and inflammatory responses. Moreover, as newly identified regulators, the mechanisms by which miRNAs, in combination with other regulatory mechanisms, control the outcome of immune responses need to be elucidated in future studies. Understanding the roles of miRNAs in regulating PRR-signalling pathways, especially TLRsignalling pathways, innate immune responses, and viral immune evasion may provide important clues for identifying novel and attractive drug targets to inflammatory diseases, cancer, autoimmunity, and infections.

\section{Conflict of Interests}

The authors declare that they have no conflict of interests.

\section{Acknowledgments}

The authors appreciate the support of the National Natural Science Funds (nos. 31302072, 31372423, and 30871884) from the National Natural Science Foundation of China and the National High Technology Research and Development Program (863 Program, no. 2011AA10A211) from the Ministry of Science and Technology of China.

\section{References}

[1] P. Broz and D. M. Monack, "Newly described pattern recognition receptors team up against intracellular pathogens," Nature Review Immunology, vol. 13, no. 8, pp. 551-565, 2013.

[2] X. B. He, H. J. Jia, Z. Z. Jing, and D. X. Liu, "Recognition of pathogen-associated nucleic acids by the intracellular toll-like receptors," Acta Biochimica et Biophysica Sinica, vol. 45, no. 4, pp. 240-257, 2013.

[3] K. Newton and V. M. Dixit, "Signaling in innate immunity and inflammation," Cold Spring Harbor in Perspectives Biology, vol. 4 , no. 3 .

[4] L. A. J. O’Neill, "When signaling pathways collide: positive and negative regulation of toll-like receptor signal transduction," Immunity, vol. 29, no. 1, pp. 12-20, 2008.

[5] T. Kondo, T. Kawai, and S. Akira, "Dissecting negative regulation of Toll-like receptor signaling," Trends in Immunology, vol. 33, no. 9, pp. 449-458, 2012.

[6] Y. K. Li and X. Y. Shi, "MicroRNAs in the regulation of TLR and RIG-I pathways," Cellular \& Molecular Immunology, vol. 10, no. 1, pp. 65-71, 2013.

[7] F. Olivieri, M. R. Rippo, F. Prattichizzo et al., "Toll-like receptor signaling ininflammaging: microRNA as new players," Immunity \& Ageing, vol. 10, no. 1, pp. 1-10, 2013.

[8] L. A. O'Neill, F. J. Sheedy, and C. E. McCoy, "MicroRNAs: the fine-tuners of Toll-like receptor signalling," Nature Reviews Immunology, vol. 11, no. 3, pp. 163-175, 2011.

[9] M. A. Nahid, M. Satoh, and E. K. L. Chan, "MicroRNA in TLR signaling and endotoxin tolerance," Cellular and Molecular Immunology, vol. 8, no. 5, pp. 388-403, 2011.

[10] X. Ma, L. E. Becker Buscaglia, J. R. Barker, and Y. Li, “MicroRNAs in NF- $\kappa$ B signaling," Journal of Molecular Cell Biology, vol. 3, no. 3, pp. 159-166, 2011. 
[11] R. Zhou, S. P. O'Hara, and X.-M. Chen, "MicroRNA regulation of innate immune responses in epithelial cells," Cellular and Molecular Immunology, vol. 8, no. 5, pp. 371-379, 2011.

[12] R. C. Coll and L. A. J. O'Neill, "New insights into the regulation of signalling by toll-like receptors and nod-like receptors," Journal of Innate Immunity, vol. 2, no. 5, pp. 406-421, 2010.

[13] L. A. Yates, C. J. Norbury, and R. J. Gilbert, "The long and short of microRNA," Cell, vol. 53, no. 3, pp. 516-519, 2013.

[14] D. P. Bartel, "MicroRNAs: target recognition and regulatory functions," Cell, vol. 136, no. 2, pp. 215-233, 2009.

[15] M. R. Fabian, N. Sonenberg, and W. Filipowicz, "Regulation of mRNA translation and stability by microRNAs," Annual Review of Biochemistry, vol. 79, pp. 351-379, 2010.

[16] C. Z. Chen, S. Schaffert, R. Fragoso, and C. Loh, "Regulation of immune responses and tolerance: the microRNA perspective," Immunological Reviews, vol. 253, no. 1, pp. 112-128, 2013.

[17] R. M. O'Connell, D. S. Rao, and D. Baltimore, "MicroRNA regulation of inflammatory responses," Annual Review of Immunology, vol. 30, pp. 295-312, 2012.

[18] R. M. O’Connell, D. S. Rao, A. A. Chaudhuri, and D. Baltimore, "Physiological and pathological roles for microRNAs in the immune system," Nature Reviews Immunology, vol. 10, no. 2, pp. 111-122, 2010.

[19] K. D. Taganov, M. P. Boldin, K.-J. Chang, and D. Baltimore, "NF$\kappa \mathrm{B}$-dependent induction of microRNA miR-146, an inhibitor targeted to signaling proteins of innate immune responses," Proceedings of the National Academy of Sciences of the United States of America, vol. 103, no. 33, pp. 12481-12486, 2006.

[20] J. Jurkin, Y. M. Schichl, R. Koeffel et al., "miR-146a is differentially expressed by myeloid dendritic cell subsets and desensitizes cells to TLR2-dependent activation," Journal of Immunology, vol. 184, no. 9, pp. 4955-4965, 2010.

[21] M. P. Boldin, K. D. Taganov, D. S. Rao et al., "miR-146a is a significant brake on autoimmunity, myeloproliferation, and cancer in mice," Journal of Experimental Medicine, vol. 208, no. 6, pp. 1189-1201, 2011.

[22] M. M. Perry, S. A. Moschos, A. E. Williams, N. J. Shepherd, H. M. Larner-Svensson, and M. A. Lindsay, "Rapid changes in microrna-146a expression negatively regulate the IL-1 $\beta$ induced inflammatory response in human lung alveolar epithelial cells1," Journal of Immunology, vol. 180, no. 8, pp. 5689-5698, 2008.

[23] J. E. Cameron, Q. Yin, C. Fewell et al., "Epstein-Barr virus latent membrane protein 1 induces cellular microRNA miR146a, a modulator of lymphocyte signaling pathways," Journal of Virology, vol. 82, no. 4, pp. 1946-1958, 2008.

[24] C. Oneyama, J. Ikeda, D. Okuzaki et al., "MicroRNA-mediated downregulation of mTOR/FGFR3 controls tumor growth induced by Src-related oncogenic pathways," Oncogene, vol. 30, no. 32, pp. 3489-3501, 2011.

[25] K. Yang, Y. S. He, X. Q. Wang et al., "MiR-146a inhibits oxidized low-density lipoprotein-induced lipid accumulation and inflammatory response via targeting toll-like receptor 4," FEBS Letters, vol. 585, no. 6, pp. 854-860, 2011.

[26] J. Hou, P. Wang, L. Lin et al., "MicroRNA-146a feedback inhibits RIG-I-dependent type I IFN production in macrophages by targeting TRAF6, IRAK1, and IRAK2," Journal of Immunology, vol. 183, no. 3, pp. 2150-2158, 2009.

[27] Y. F. Xie, R. Shu, S. Y. Jiang, D. L. Liu, J. Ni, and X. L. Zhang, "MicroRNA-146 inhibits pro-inflammatory cytokine secretion through IL-1 receptor-associated kinase 1 in human gingival fibroblasts," Journal of Inflammation, vol. 10, no. 1, p. 20, 2013.
[28] S. Li, Y. Yue, W. Xu, and S. Xiong, "MicroRNA-146a represses mycobacteria-induced inflammatory response and facilitates bacterial replication via targeting IRAK-1 and TRAF-6," PLoS One, vol. 8, no. 12, Article ID e81438, 2013.

[29] B. Tang, B. Xiao, Z. Liu et al., "Identification of MyD88 as a novel target of miR-155, involved in negative regulation of Helicobacter pylori-induced inflammation," FEBS Letters, vol. 584, no. 8, pp. 1481-1486, 2010.

[30] G. Xu, Z. Zhang, Y. Xing et al., "MicroRNA-149 negatively regulates TLR-triggered inflammatory response in mouse macrophages by targeting MyD88," Journal of Cellular Biochemistry, vol. 115, no. 5, pp. 919-927, 2014.

[31] D. T. Starczynowski, F. Kuchenbauer, B. Argiropoulos et al., "Identification of miR-145 and miR-146a as mediators of the 5qsyndrome phenotype," Nature Medicine, vol. 16, no. 1, pp. 49-58, 2010.

[32] J. Worm, J. Stenvang, A. Petri et al., "Silencing of microRNA155 in mice during acute inflammatory response leads to derepression of c/ebp Beta and down-regulation of G-CSF," Nucleic Acids Research, vol. 37, no. 17, Article ID gkp577, pp. 5784-5792, 2009.

[33] S. Costinean, S. K. Sandhu, I. M. Pedersen et al., "Src homology 2 domain-containing inositol-5-phosphatase and CCAAT enhancer-binding protein $\beta$ are targeted by miR-155 in B cells of E $\mu$-MiR-155 transgenic mice," Blood, vol. 114, no. 7, pp. 13741382, 2009.

[34] S. Kohlhaas, O. A. Garden, C. Scudamore, M. Turner, K. Okkenhaug, and E. Vigorito, "Cutting edge: the Foxp3 target miR-155 contributes to the development of regulatory T cellsl," Journal of Immunology, vol. 182, no. 5, pp. 2578-2582, 2009.

[35] Y. Bai, C. Qian, L. Qian et al., "Integrin CD11b negatively regulates TLR9-triggered dendritic cell cross-priming by upregulating microRNA-146a," Journal of Immunology, vol. 188, no. 11, pp. 5293-5302, 2012.

[36] R. M. O’Connell, K. D. Taganov, M. P. Boldin, G. Cheng, and D. Baltimore, "MicroRNA-155 is induced during the macrophage inflammatory response," Proceedings of the National Academy of Sciences of the United States of America, vol. 104, no. 5, pp. 16041609, 2007.

[37] G. Gatto, A. Rossi, D. Rossi, S. Kroening, S. Bonatti, and M. Mallardo, "Epstein-Barr virus latent membrane protein 1 transactivates miR-155 transcription through the NF- $\kappa$ B pathway," Nucleic Acids Research, vol. 36, no. 20, pp. 6608-6619, 2008.

[38] M. Ceppi, A. M. Pereira, I. Dunand-Sauthier et al., "MicroRNA155 modulates the interleukin-1 signaling pathway in activated human monocyte-derived dendritic cells," Proceedings of the National Academy of Sciences of the United States of America, vol. 106, no. 8, pp. 2735-2740, 2009.

[39] Y. Cheng, W. Kuang, Y. Hao et al., "Downregulation of miR-27a* and miR-532-5p and Upregulation of miR-146a and miR-155 in LPS-induced RAW264.7 Macrophage Cells," Inflammation, vol. 35, no. 4, pp. 1308-1313, 2012.

[40] E. Tili, J.-J. Michaille, A. Cimino et al., "Modulation of miR155 and miR-125b levels following lipopolysaccharide/TNF- $\alpha$ stimulation and their possible roles in regulating the response to endotoxin shock," Journal of Immunology, vol. 179, no. 8, pp. 5082-5089, 2007.

[41] Q. Yin, X. Wang, J. McBride, C. Fewell, and E. Flemington, "B-cell receptor activation induces BIC/miR-155 expression through a conserved AP-1 element," The Journal of Biological Chemistry, vol. 283, no. 5, pp. 2654-2662, 2008. 
[42] T.-H. Thai, D. P. Calado, S. Casola et al., "Regulation of the germinal center response by MicroRNA-155," Science, vol. 316, no. 5824, pp. 604-608, 2007.

[43] H. An, H. Xu, M. Zhang et al., "Src homology 2 domaincontaining inositol-5-phosphatase 1 (SHIP1) negatively regulates TLR4-mediated LPS response primarily through a phosphatase activity- and PI-3K-independent mechanism," Blood, vol. 105, no. 12, pp. 4685-4692, 2005.

[44] R. M. O'Connell, A. A. Chaudhuri, D. S. Rao, and D. Baltimore, "Inositol phosphatase SHIP1 is a primary target of miR-155," Proceedings of the National Academy of Sciences of the United States of America, vol. 106, no. 17, pp. 7113-7118, 2009.

[45] T. J. Cremer, D. H. Ravneberg, C. D. Clay et al., "MiR-155 induction by F. novicida but not the virulent F. tularensis results in SHIP down-regulation and enhanced pro-inflammatory cytokine response," PLoS ONE, vol. 4, no. 12, Article ID e8508, 2009.

[46] J. N. Gabhann, R. Higgs, K. Brennan et al., "Absence of SHIP-1 results in constitutive phosphorylation of tank-binding kinase 1 and enhanced TLR3-dependent IFN- $\beta$ production," Journal of Immunology, vol. 184, no. 5, pp. 2314-2320, 2010.

[47] P. Wang, J. Hou, L. Lin et al., "Inducible microRNA-155 feedback promotes type I IFN signaling in antiviral innate immunity by targeting suppressor of cytokine signaling 1," Journal of Immunology, vol. 185, no. 10, pp. 6226-6233, 2010.

[48] C. E. McCoy, F. J. Sheedy, J. E. Qualls et al., "IL-10 inhibits miR155 induction by toll-like receptors," The Journal of Biological Chemistry, vol. 285, no. 27, pp. 20492-20498, 2010.

[49] I. Shaked, A. Meerson, Y. Wolf et al., "MicroRNA-132 potentiates cholinergic anti-inflammatory signaling by targeting acetylcholinesterase," Immunity, vol. 31, no. 6, pp. 965-973, 2009.

[50] D. Lagos, G. Pollara, S. Henderson et al., "MiR-132 regulates antiviral innate immunity through suppression of the p300 transcriptional co-activator," Nature Cell Biology, vol. 12, no. 5, pp. 513-519, 2010.

[51] M. A. Nahid, B. Yao, P. R. Dominguez-Gutierrez, L. Kesavalu, M. Satoh, and E. K. Chan, "Regulation of TLR2-mediated tolerance and cross-tolerance through IRAK4 modulation by miR132 and miR-212," The Journal of Immunology, vol. 190, no. 3, pp. 1250-6123, 2013.

[52] S. A. Moschos, A. E. Williams, M. M. Perry, M. A. Birrell, M. G. Belvisi, and M. A. Lindsay, "Expression profiling in vivo demonstrates rapid changes in lung microRNA levels following lipopolysaccharide-induced inflammation but not in the antiinflammatory action of glucocorticoids," BMC Genomics, vol. 8, article 240, 2007.

[53] J. B. Johnnidis, M. H. Harris, R. T. Wheeler et al., "Regulation of progenitor cell proliferation and granulocyte function by microRNA-223," Nature, vol. 451, no. 7182, pp. 1125-1129, 2008.

[54] Y. Chen, J. Chen, H. Wang et al., "HCV-induced miR-21 contributes to evasion of host immune system by targeting MyD88 and IRAK1," PLoS Pathogens, vol. 9, no. 4, Article ID e1003248, 2013.

[55] Q. Y. Chen, H. Wang, Y. Liu et al., "Inducible microRNA223 down-regulation promotes TLR-triggered IL-6 and IL-1b production in macrophages by targeting STAT3," PLoS One, vol. 7, no. 8, Article ID e42971, 2012.

[56] Z. Huang, X. Chen, B. Yu, and D. Chen, "Cloning and functional characterization of rat stimulator of interferon genes (STING) regulated by miR-24," Developmental and Comparative Immunology, vol. 37, no. 3-4, pp. 414-420, 2012.
[57] G. Liu, A. Friggeri, Y. Yang, Y.-J. Park, Y. Tsuruta, and E. Abraham, "miR-147, a microRNA that is induced upon toll-like receptor stimulation, regulates murine macrophage inflammatory responses," Proceedings of the National Academy of Sciences of the United States of America, vol. 106, no. 37, pp. 15819-15824, 2009.

[58] F. Bazzoni, M. Rossato, M. Fabbri et al., "Induction and regulatory function of miR-9 in human monocytes and neutrophils exposed to proinflammatory signals," Proceedings of the National Academy of Sciences of the United States of America, vol. 106, no. 13, pp. 5282-5287, 2009.

[59] C. Jennewein, A. Von Knethen, T. Schmid, and B. Brüne, "MicroRNA-27b contributes to lipopolysaccharide-mediated peroxisome proliferator-activated receptor $\gamma$ (PPAR $\gamma)$ mRNA destabilization," The Journal of Biological Chemistry, vol. 285, no. 16, pp. 11846-11853, 2010.

[60] R. Zhou, G. Hu, A.-Y. Gong, and X.-M. Chen, "Binding of NFkappaB p65 subunit to the promoter elements is involved in LPS-induced transactivation of miRNA genes in human biliary epithelial cells," Nucleic Acids Research, vol. 38, no. 10, Article ID gkq056, pp. 3222-3232, 2010.

[61] R. Zhou, G. Hu, J. Liu, A.-Y. Gong, K. M. Drescher, and X.-M. Chen, "NF-kappaB p65-dependent transactivation of miRNA genes following Cryptosporidium parvum infection stimulates epithelial cell immune responses," PLoS Pathogens, vol. 5, no. 12, Article ID e1000681, 2009.

[62] A. Androulidaki, D. Iliopoulos, A. Arranz et al., "The kinase Akt1 controls macrophage response to lipopolysaccharide by regulating MicroRNAs," Immunity, vol. 31, no. 2, pp. 220-231, 2009.

[63] F. J. Sheedy, E. Palsson-Mcdermott, E. J. Hennessy et al., "Negative regulation of TLR4 via targeting of the proinflammatory tumor suppressor PDCD4 by the microRNA miR-21," Nature Immunology, vol. 11, no. 2, pp. 141-147, 2010.

[64] V. Y. Shin, H. Jin, E. K. O. Ng et al., "NF- $\kappa$ B targets miR-16 and miR-21 in gastric cancer: involvement of prostaglandin $\mathrm{E}$ receptors," Carcinogenesis, vol. 32, no. 2, pp. 240-245, 2011.

[65] S. Fujita, T. Ito, T. Mizutani et al., "miR-21 gene expression triggered by AP-1 is sustained through a double-negative feedback mechanism," Journal of Molecular Biology, vol. 378, no. 3, pp. 492-504, 2008.

[66] A. Misawa, R. Katayama, S. Koike, A. Tomida, T. Watanabe, and N. Fujita, "AP-1-dependent miR-21 expression contributes to chemoresistance in cancer stem cell-like SP cells," Oncology Research, vol. 19, no. 1, pp. 23-33, 2010.

[67] V. Palanisamy, A. Jakymiw, E. A. van Tubergen, N. J. D. Silva, and K. L. Kirkwood, "Control of cytokine mRNA expression by RNA-binding proteins and microRNAs," Journal of Dental Research, vol. 91, no. 7, pp. 651-658, 2012.

[68] G. Stoecklin, S. A. Tenenbaum, T. Mayo et al., "Genomewide analysis identifies interleukin-10 mRNA as target of tristetraprolin," The Journal of Biological Chemistry, vol. 283, no. 17, pp. 11689-11699, 2008.

[69] G. Alsaleh, G. Suffert, N. Semaan et al., "Bruton's tyrosine kinase is involved in miR-346-related regulation of IL-18 release by lipopolysaccharide-activated rheumatoid fibroblast-like synoviocytes," Journal of Immunology, vol. 182, no. 8, pp. 5088-5097, 2009.

[70] Z. Lu, Y. Li, A. Takwi et al., "miR-301a as an NF- $\kappa$ B activator in pancreatic cancer cells," The EMBO Journal, vol. 30, no. 1, pp. 57-67, 2011. 
[71] M. Shao, S. Rossi, B. Chelladurai et al., "PDGF induced microRNA alterations in cancer cells," Nucleic Acids Research, vol. 39, no. 10, pp. 4035-4047, 2011.

[72] S. P. O’Hara, P. L. Splinter, G. B. Gajdos et al., "NFkB p50CCAAT/enhancer-binding protein $\beta(\mathrm{C} / \mathrm{EBP} \beta)$-mediated transcriptional repression of microRNA let-7i following microbial infection," The Journal of Biological Chemistry, vol. 285, no. 1, pp. 216-225, 2010.

[73] X.-M. Chen, P. L. Splinter, S. P. O’Hara, and N. F. LaRusso, "A cellular micro-RNA, let-7i, regulates toll-like receptor 4 expression and contributes to cholangiocyte immune responses against Cryptosporidium parvum infection," The Journal of Biological Chemistry, vol. 282, no. 39, pp. 28929-28938, 2007.

[74] D. Iliopoulos, H. A. Hirsch, and K. Struhl, "An epigenetic switch involving NF- $\kappa$ B, Lin28, let-7 MicroRNA, and IL6 links inflammation to cell transformation," Cell, vol. 139, no. 4, pp. 693-706, 2009.

[75] G. Hu, R. Zhou, J. Liu et al., "MicroRNA-98 and let-7 confer cholangiocyte expression of cytokine-inducible Src homology 2 -containing protein in response to microbial challenge," Journal of Immunology, vol. 183, no. 3, pp. 1617-1624, 2009.

[76] S. Liu, L. C. Wu, J. Pang et al., "Sp1/NFkappaB/HDAC/miR-29b regulatory network in KIT-driven myeloid leukemia," Cancer Cell, vol. 17, no. 4, pp. 333-347, 2010.

[77] H. Wang, R. Garzon, H. Sun et al., "NF- $\kappa B-Y Y 1-m i R-29$ regulatory circuitry in skeletal myogenesis and rhabdomyosarcoma," Cancer Cell, vol. 14, no. 5, pp. 369-381, 2008.

[78] L. Tserel, T. Runnel, K. Kisand et al., "MicroRNA expression profiles of human blood monocyte-derived dendritic cells and macrophages reveal miR-511 as putative positive regulator of toll-like receptor 4," The Journal of Biological Chemistry, vol. 286, no. 30, pp. 26487-26495, 2011.

[79] G. Curtale, M. Mirolo, T. A. Renzi, M. Rossato, F. Bazzoni, and M. Locati, "Negative regulation of Toll-like receptor 4 signaling by IL-10-dependent microRNA-146b," Proceedings of the National Academy of Sciences of the United States of America, vol. 110, no. 28, pp. 11449-11504, 2013.

[80] C. Jiang, W. Zhu, J. Xu et al., "MicroRNA-26a negatively regulates toll-like receptor 3 expression of rat macrophages and ameliorates pristane induced arthritis in rats," Arthritis Research \& Therapy, vol. 16, no. 1, p. R9, 2014.

[81] E. M. Quinn, J. H. Wang, G. O'Callaghan, and H. P. Redmond, "MicroRNA-146a is upregulated by and negatively regulates TLR2 signaling," PLoS One, vol. 8, no. 4, Article ID e62232, 2013.

[82] M. R. Benakanakere, Q. Li, M. A. Eskan et al., "Modulation of TLR2 protein expression by miR-105 in human oral keratinocytes," The Journal of Biological Chemistry, vol. 284, no. 34, pp. 23107-23115, 2009.

[83] L. Philippe, G. Alsaleh, G. Suffert et al., “TLR2 expression is regulated by microRNA miR-19 in rheumatoid fibroblast-like synoviocytes," Journal of Immunology, vol. 188, no. 1, pp. 454461, 2012.

[84] H. Guo, Y. Chen, X. Hu, G. Qian, S. Ge, and J. Zhang, "The regulation of toll-like receptor 2 by miR-143 suppresses the invasion and migration of a subset of human colorectal carcinoma cells," Molecular Cancer, vol. 12, p. 77, 2013.

[85] L. Lin, J. Hou, F. Ma et al., "Type I IFN inhibits innate IL-10 production in macrophages through histone deacetylase 11 by downregulating microRNA-145," The Journal of Immunology, vol. 191, no. 7, pp. 3896-3904, 2013.

[86] J. Wei, X. Huang, Z. Zhang et al., "MyD88 as a target of microRNA-203 in regulation of lipopolysaccharide or Bacille
Calmette-Guerin induced inflammatory response of macrophage RAW264.7 cells," Molecular Immunology, vol. 55, no. 34, pp. 303-309, 2013.

[87] R.-S. Huang, G.-Q. Hu, B. Lin, Z.-Y. Lin, and C.-C. Sun, "Microrna-155 silencing enhances inflammatory response and lipid uptake in oxidized low-density lipoprotein-stimulated human THP-1 macrophages," Journal of Investigative Medicine, vol. 58, no. 8, pp. 961-967, 2010.

[88] E. B. Wendlandt, J. W. Graff, T. L. Gioannini, A. P. McCaffrey, and M. E. Wilson, "The role of MicroRNAs miR-200b and miR$200 \mathrm{c}$ in TLR4 signaling and NF- $\kappa \mathrm{B}$ activation," Innate Immunity, vol. 18, no. 6, pp. 846-855, 2012.

[89] F. Ahmed, T. Shiraishi, R. L. Vessella, and P. Kulkarni, “Tumor necrosis factor receptor associated factor-4: an adapter protein overexpressed in metastatic prostate cancer is regulated by microRNA-29a," Oncology Reports, vol. 30, no. 6, pp. 29632968, 2013.

[90] N. J. Horwood, T. Mahon, J. P. McDaid et al., "Bruton's tyrosine kinase is required for lipopolysaccharide-induced tumor necrosis factor $\alpha$ production," Journal of Experimental Medicine, vol. 197, no. 12, pp. 1603-1611, 2003.

[91] T. Li, M. J. Morgan, S. Choksi, Y. Zhang, Y.-S. Kim, and Z.G. Liu, "MicroRNAs modulate the noncanonical transcription factor NF- $\kappa \mathrm{B}$ pathway by regulating expression of the kinase IKK $\alpha$ during macrophage differentiation," Nature Immunology, vol. 11, no. 9, pp. 799-805, 2010.

[92] L. Lai, Y. Song, Y. Liu et al., "MicroRNA-92a negatively regulates Toll-like receptor (TLR)- triggered inflammatory response in macrophages by targeting MKK4 kinase," The Journal of Biological Chemistry, vol. 288, no. 11, pp. 7956-7967, 2013.

[93] J. Qi, Y. Qiao, P. Wang, S. Li, W. Zhao, and C. Gao, "MicroRNA210 negatively regulates LPS-induced production of proinflammatory cytokines by targeting NF- $\kappa \mathrm{B} 1$ in murine macrophages," FEBS Letters, vol. 586, no. 8, pp. 1201-1207, 2012.

[94] M. Garg, J. A. Potter, and V. M. Abrahams, "Identification of microRNAs that regulate TLR2-mediated trophoblast apoptosis and inhibition of IL-6 mRNA," PLoS One, vol. 8, no. 10, Article ID e77249, 2013.

[95] M. Zhang, Q. Liu, S. Mi et al., "Both miR-17-5p and miR-20a alleviate suppressive potential of myeloid-derived suppressor cells by modulating STAT3 expression," Journal of Immunology, vol. 186, no. 8, pp. 4716-4724, 2011.

[96] S. R. Quinn, N. E. Mangan, B. E. Caffrey et al., “The role of Ets2 transcription factor in the induction of MicroRNA-155 (miR$155)$ by lipopolysaccharide and its targeting by interleukin-10," The Journal of Biological Chemistry, vol. 289, no. 7, pp. 43164325, 2014.

[97] Q. Jing, S. Huang, S. Guth et al., "Involvement of MicroRNA in AU-Rich Element-Mediated mRNA Instability," Cell, vol. 120, no. 5, pp. 623-634, 2005.

[98] Y. Li, X. Fan, X. He et al., "MicroRNA-466l inhibits antiviral innate immune response by targeting interferon-alpha," Cellular \& Molecular Immunology, vol. 9, no. 6, pp. 495-502, 2012.

[99] K. W. Witwer, J. M. Sisk, L. Gama, and J. E. Clements, "MicroRNA regulation of IFN- $\beta$ protein expression: rapid and sensitive modulation of the innate immune response," Journal of Immunology, vol. 184, no. 5, pp. 2369-2376, 2010.

[100] M. Rossato, G. Curtale, N. Tamassia et al., "IL-10-induced microRNA-187 negatively regulates TNF-, IL-6, and IL-12p40 production in TLR4-stimulated monocytes," Proceedings of the National Academy of Sciences of the United States of America, vol. 109, no. 45, pp. E3101-E3110, 2012. 
[101] M. El Gazzar and C. E. McCall, "MicroRNAs distinguish translational from transcriptional silencing during endotoxin tolerance," The Journal of Biological Chemistry, vol. 285, no. 27, pp. 20940-20951, 2010.

[102] S. Vasudevan and J. A. Steitz, "AU-Rich-Element-Mediated upregulation of translation by FXR1 and argonaute 2," Cell, vol. 128, no. 6, pp. 1105-1118, 2007.

[103] Z. Xu, S.-B. Xiao, P. Xu et al., "miR-365, a novel negative regulator of interleukin- 6 gene expression, is cooperatively regulated by Sp1 and NF- $\kappa \mathrm{B}$," The Journal of Biological Chemistry, vol. 286, no. 24, pp. 21401-21412, 2011.

[104] Y. Sun, S. Varambally, C. A. Maher et al., "Targeting of microRNA-142-3p in dendritic cells regulates endotoxininduced mortality," Blood, vol. 117, no. 23, pp. 6172-6183, 2011.

[105] A. Sharma, M. Kumar, J. Aich et al., "Posttranscriptional regulation of interleukin-10 expression by hsa-miR-106a," Proceedings of the National Academy of Sciences of the United States of America, vol. 106, no. 14, pp. 5761-5766, 2009.

[106] F. Ma, X. Liu, D. Li et al., "MicroRNA-4661 upregulates IL10 expression in TLR-triggered macrophages by antagonizing RNA-binding protein tristetraprolin-mediated IL-10 mRNA degradation," Journal of Immunology, vol. 184, no. 11, pp. 60536059, 2010.

[107] T. X. Lu, A. Munitz, and M. E. Rothenberg, "MicroRNA-21 is up-regulated in allergic airway inflammation and regulates IL12p35 expression," Journal of Immunology, vol. 182, no. 8, pp. 4994-5002, 2009.

[108] T. X. Lu, J. Hartner, E.-J. Lim et al., "MicroRNA-21 limits in vivo immune response-mediated activation of the IL-12/IFN- $\gamma$ pathway, Th1 polarization, and the severity of delayed-type hypersensitivity," Journal of Immunology, vol. 187, no. 6, pp. 33623373, 2011.

[109] Z. Wu, H. Lu, J. Sheng, and L. Li, "Inductive microRNA-21 impairs anti-mycobacterial responses by targeting IL-12 and Bcl-2," FEBS Letters, vol. 586, no. 16, pp. 2459-2467, 2012.

[110] F. Ma, S. Xu, X. Liu et al., "The microRNA miR-29 controls innate and adaptive immune responses to intracellular bacterial infection by targeting interferon- $\gamma$," Nature Immunology, vol. 12 , no. 9, pp. 861-869, 2011.

[111] H.-S. Yang, A. P. Jansen, A. A. Komar et al., "The transformation suppressor Pdcd4 is a novel eukaryotic translation initiation factor 4A binding protein that inhibits translation," Molecular and Cellular Biology, vol. 23, no. 1, pp. 26-37, 2003.

[112] P. G. Loh, H.-S. Yang, M. A. Walsh et al., "Structural basis for translational inhibition by the tumour suppressor Pdcd4," The EMBO Journal, vol. 28, no. 3, pp. 274-285, 2009.

[113] Y. Sun, J. Cai, F. Ma, P. Lü, H. Huang, and J. Zhou, “miR-155 mediates suppressive effect of progesterone on TLR3, TLR4triggered immune response," Immunology Letters, vol. 146, no. 1-2, pp. 25-30, 2012.

[114] X. Liu, Z. Zhan, L. Xu et al., "MicroRNA-148/152 impair innate response and antigen presentation of TLR-triggered dendritic cells by targeting CaMKII $\alpha$," Journal of Immunology, vol. 185, no. 12, pp. 7244-7251, 2010.

[115] J. Zhao, A.-Y. Gong, R. Zhou, J. Liu, A. N. Eischeid, and X.M. Chen, "Downregulation of PCAF by miR-181a/b provides feedback regulation to TNF- $\alpha$-induced transcription of proinflammatory genes in liver epithelial cells," Journal of Immunology, vol. 188, no. 3, pp. 1266-1274, 2012.

[116] R. Triboulet, B. Mari, Y.-L. Lin et al., "Suppression of MicroRNA-silencing pathway by HIV-1 during virus replication," Science, vol. 315, no. 5818, pp. 1579-1582, 2007.
[117] G. Hu, R. Zhou, J. Liu, A.-Y. Gong, and X.-M. Chen, "MicroRNA-98 and let-7 regulate expression of suppressor of cytokine signaling 4 in biliary epithelial cells in response to Cryptosporidium parvum infection," Journal of Infectious Diseases, vol. 202, no. 1, pp. 125-135, 2010.

[118] E. Sonkoly, T. Wei, P. C. J. Janson et al., "MicroRNAs: novel regulators involved in the pathogenesis of psoriasis?" PloS One, vol. 2, no. 7, p. e610, 2007.

[119] Z. Qing-Yuan, L. Qin, C. Jian-Xia, L. Ke, and G. Bao-Xue, "MicroRNA-101 targets MAPK phosphatase-1 to regulate the activation of MAPKs in macrophages," Journal of Immunology, vol. 185, no. 12, pp. 7435-7442, 2010.

[120] N. H. Foley and L. A. F. O'Neill, "MiR-107: a toll-like receptorregulated miRNA dysregulated in obesity and type II diabetes," Journal of Leukocyte Biology, vol. 92, no. 3, pp. 521-527, 2012.

[121] R. K. Kutty, C. N. Nagineni, W. Samuel et al., "Differential regulation of microRNA-146a and microRNA-146b-5p in human retinal pigment epithelial cells by interleukin-1 $\beta$, tumor necrosis factor- $\alpha$, and interferon- $\gamma$," Molecular Vision, vol. 19, pp. 737-750, 2013.

[122] R. Chen, A. B. Alvero, D. A. Silasi et al., "Regulation of IKK $\beta$ by miR-199a affects NF- $\kappa$ B activity in ovarian cancer cells," Oncogene, vol. 27, no. 34, pp. 4712-4723, 2008.

[123] L. Dai, L. Gu, and W. Di, "MiR-199a attenuates endometrial stromal cell invasiveness through suppression of the IKK $\beta / \mathrm{nf}$ $\kappa \mathrm{b}$ pathway and reduced interleukin-8 expression," Molecular Human Reproduction, vol. 18, no. 3, Article ID gar066, pp. 136145, 2012.

[124] N. J. Martinez and A. J. M. Walhout, "The interplay between transcription factors and microRNAs in genome-scale regulatory networks," BioEssays, vol. 31, no. 4, pp. 435-445, 2009.

[125] W. Filipowicz, S. N. Bhattacharyya, and N. Sonenberg, "Mechanisms of post-transcriptional regulation by microRNAs: are the answers in sight?" Nature Reviews Genetics, vol. 9, no. 2, pp. 102114,2008

[126] A. J. Asirvatham, C. J. Gregorie, Z. Hu, W. J. Magner, and T. B. Tomasi, "MicroRNA targets in immune genes and the Dicer/Argonaute and ARE machinery components," Molecular Immunology, vol. 45, no. 7, pp. 1995-2006, 2008.

[127] A. J. Asirvatham, W. J. Magner, and T. B. Tomasi, "miRNA regulation of cytokine genes," Cytokine, vol. 45, no. 2, pp. 5869, 2009.

[128] X. Liu and S. I. Rennard, "MicroRNA and cytokines," Molecular and Cellular Pharmacology, vol. 3, no. 3, pp. 143-151, 2011.

[129] P. Wang, Y. Gu, Q. Zhang et al., "Identification of resting and type I IFN-activated human NK cell miRNomes reveals microRNA-378 and microRNA-30e as negative regulators of NK cell cytotoxicity," The Journal of Immunology, vol. 189, no. 1, pp. 211-221, 2012.

[130] A. S. Papadopoulou, J. Dooley, M. A. Linterman et al., "The thymic epithelial microRNA network elevates the threshold for infection-associated thymic involution via miR-29a mediated suppression of the IFN- $\alpha$ receptor," Nature Immunology, vol. 13, no. 2, pp. 181-187, 2012.

[131] M. A. Nahid, K. M. Pauley, M. Satoh, and E. K. L. Chan, "miR146a is critical for endotoxin-induced tolerance: implication in innate immunity," The Journal of Biological Chemistry, vol. 284, no. 50, pp. 34590-34599, 2009.

[132] S. J. Li, Z. Chen, and H. H. Zhu, "Influence of miR-122 on IFNalpha treatment for HCV infection," Zhejiang Da Xue Xue Bao Yi Xue Ban, vol. 40, no. 6, pp. 588-592, 2011. 
[133] M. Haneklaus, M. Gerlic, M. Kurowska-Stolarska et al., "Cutting edge: miR-223 and EBV miR-BART15 regulate the NLRP3 inflammasome and IL-1beta production," Journal of Immunology, vol. 189, no. 8, pp. 3795-3799, 2012.

[134] F. Bauernfeind, A. Rieger, F. A. Schildberg et al., "NLRP3 inflammasome activity is negatively controlled by miR-223," Journal of Immunology, vol. 189, no. 8, pp. 4175-4181, 2012.

[135] S. Pfeffer, M. Zavolan, F. A. Grässer et al., "Identification of virus-encoded MicroRNAs," Science, vol. 304, no. 5671, pp. 734736, 2004.

[136] R. Grassmann and K.-T. Jeang, "The roles of microRNAs in mammalian virus infection," Biochimica et Biophysica Acta: Gene Regulatory Mechanisms, vol. 1779, no. 11, pp. 706-711, 2008.

[137] R. L. Skalsky and B. R. Cullen, "Viruses, microRNAs, and host interactions," Annual Review of Microbiology, vol. 64, pp. 123141, 2010.

[138] A. Grundhoff and C. S. Sullivan, "Virus-encoded microRNAs," Virology, vol. 411, no. 2, pp. 325-343, 2011.

[139] J. R. Abend, D. Ramalingam, P. Kieffer-Kwon, T. S. Uldrick, R. Yarchoan, and J. M. Ziegelbauer, "Kaposi's sarcoma-associated herpesvirus microRNAs target IRAK1 and MYD88, two components of the toll-like receptor/interleukin-1R signaling cascade, to reduce inflammatory-cytokine expression," Journal of Virology, vol. 86, no. 21, pp. 11663-11674, 2012.

[140] R. P. Kincaid and C. S. Sullivan, "Virus-encoded microRNAs: an overview and a look to the future," PLoS Pathogens, vol. 8, no. 12, Article ID e1003018, 2012.

[141] B. R. Cullen, "MicrorNAs as mediators of viral evasion of the immune system," Nature Immunology, vol. 14, no. 3, pp. 205210, 2013.

[142] M. Fabbri, A. Paone, F. Calore et al., "MicroRNAs bind to Tolllike receptors to induce prometastatic inflammatory response," Proceedings of the National Academy of Sciences of the United States of America, vol. 109, no. 31, pp. E2110-E2116, 2012.

[143] S. M. Lehmann, C. Kruger, B. Park et al., "An unconventional role for miRNA: let-7 activates Toll-like receptor 7 and causes neurodegeneration," Nature Neuroscience, vol. 15, no. 6, pp. 827835, 2012.

[144] M. Fabbri, “TLRs as miRNA receptors," Cancer Research, vol. 72, no. 24, pp. 6333-6337, 2012.

[145] M. Fabbri, A. Paone, F. Calore, R. Galli, and C. M. Croce, "A new role for microRNAs, as ligands of Toll-like receptors," RNA Biology, vol. 10, no. 2, pp. 1-6, 2013.

[146] X. Chen, H. W. Liang, J. F. Zhang, K. Zen, and C. Y. Zhang, "microRNAs are ligands of Toll-like receptors," RNA, vol. 19, no. 6, pp. 737-739, 2013. 


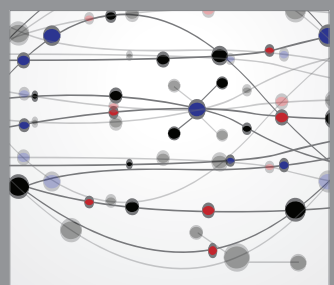

The Scientific World Journal
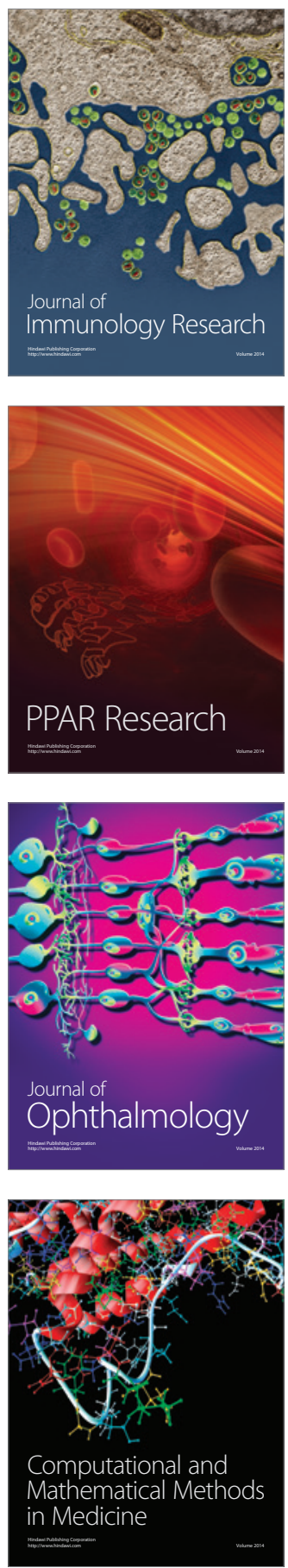

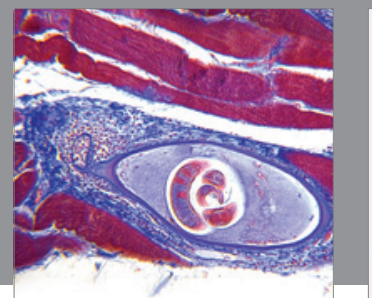

Gastroenterology

Research and Practice
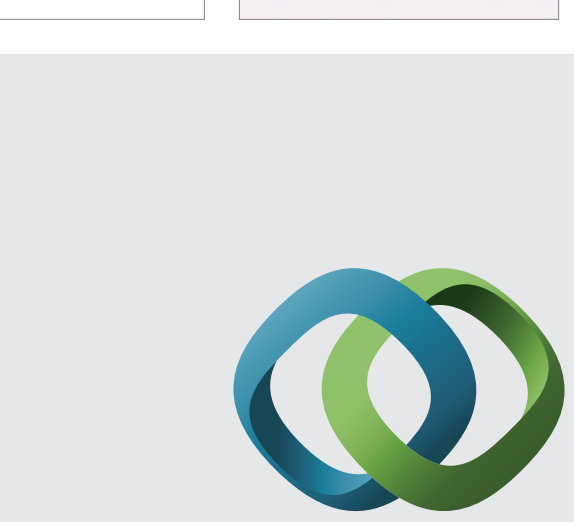

\section{Hindawi}

Submit your manuscripts at

http://www.hindawi.com
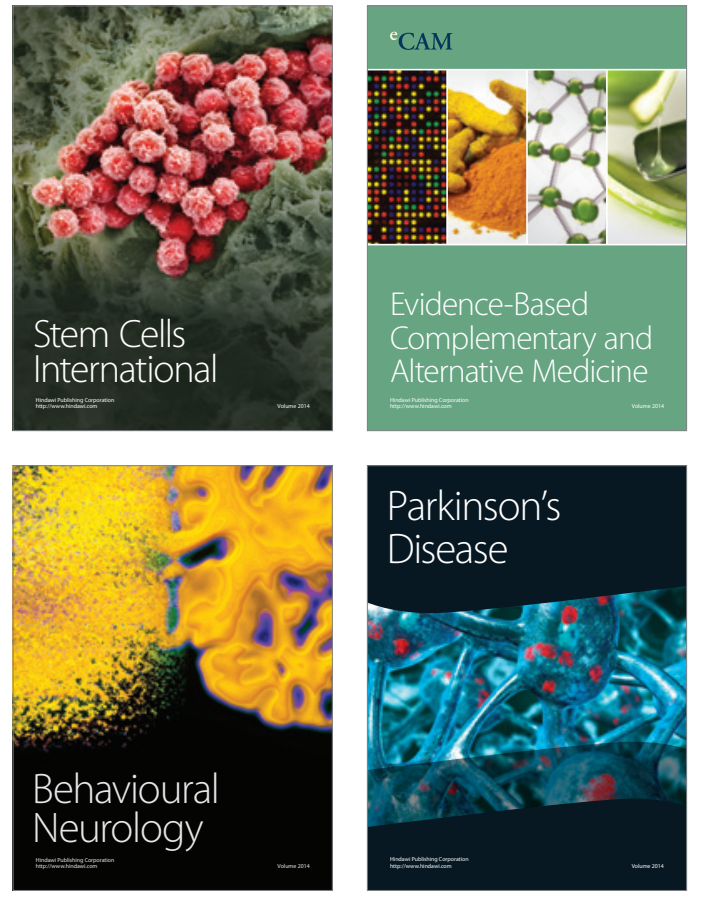
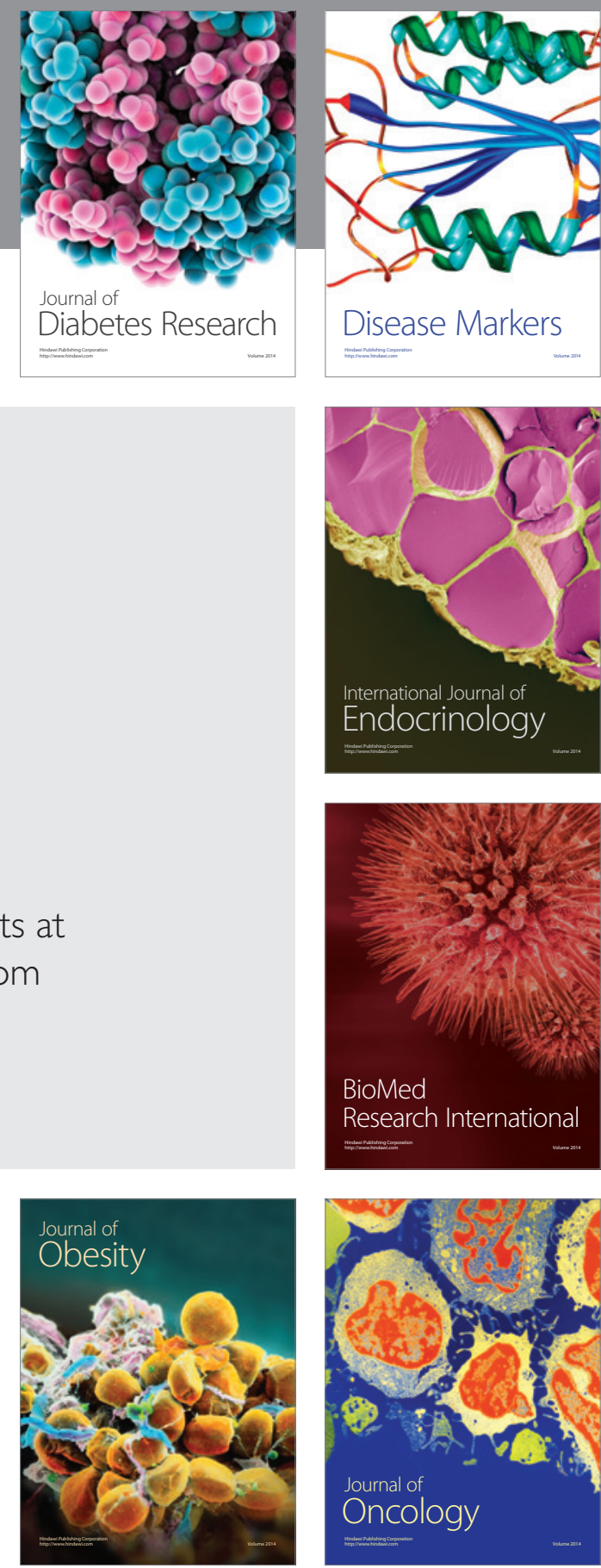

Disease Markers
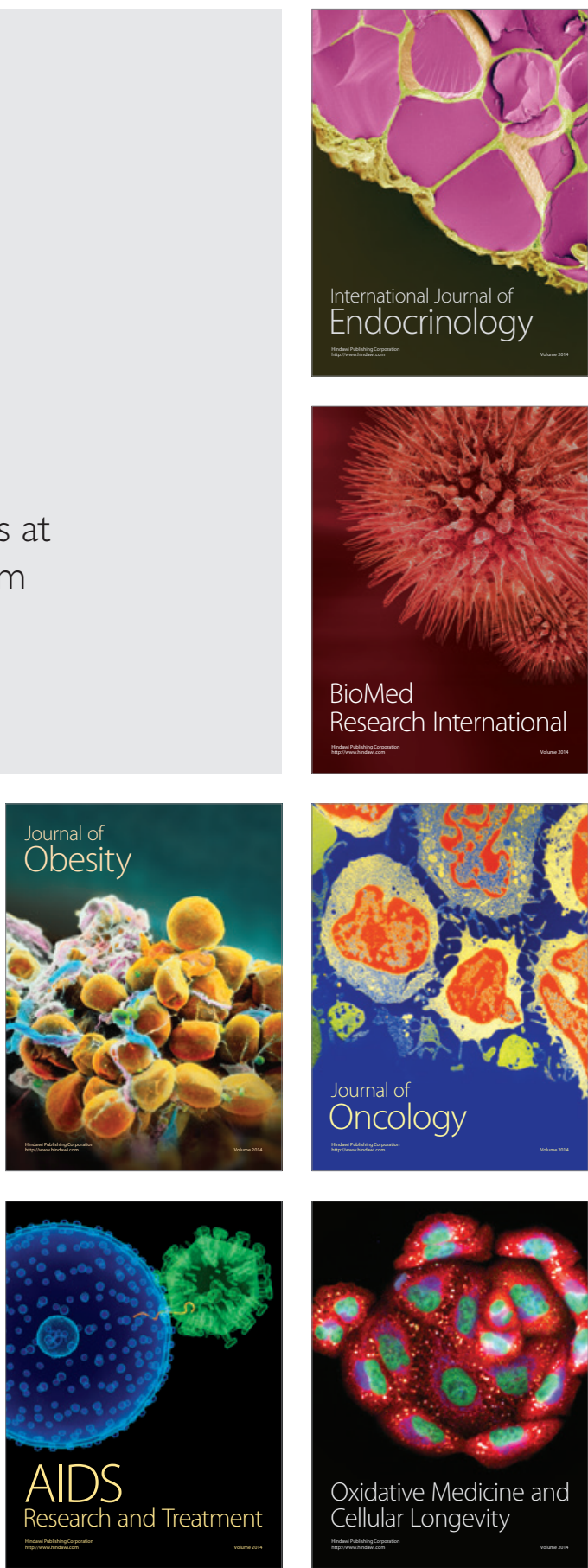